\title{
Las artesanías y su real impacto en el turismo
}

\section{(c) $(i)$ (i) (2)}

Handicrafts and their real impact on tourism

Efraín Velasteguí López. ${ }^{1}$

Recibido: 03-03-2019 / Revisado: 10-03-2019 / Aceptado: 26-03-2019 / Publicado: 05-04-2019

Resumen.

DOI: https://doi.org/10.33262/concienciadigital.v2i2.942

La artesanía es un importante recurso para un turismo que gusta de apreciar las expresiones populares del arte en diversos materiales. Por ello, la artesanía de fibra vegetal (arbusto de perlilla) que se realiza en el Ecuador, es un producto cultural y natural que reproduce piezas como venados, canastas, patos y cisnes, pero sobre todo nacimientos, ángeles, trineos y Santa Claus, que son figuras asociadas a la Navidad (periodo del año en el que se venden más estas artesanías).

El binomio recursos naturales y cultura ha sido exitoso en otros países que han visto aumentar los ingresos económicos de sus poblaciones rurales con proyectos que resaltan las peculiaridades culturales de su gente y las bellezas naturales de su entorno. Algunos ejemplos los encontramos en Bahía, donde se promueve el arte y el patrimonio histórico de esta ciudad como reclamo turístico, o el caso de España con una oferta muy amplia de turismo rural basado en lo gastronómico, asociado a fiestas, actos religiosos y eventos sociales, que atrae a numerosos turistas degustadores de la comida tradicional, quienes siguen rutas gastronómicas de productos típicos.

La masificación del turismo se consideró que los únicos que disponían de tiempo libre eran una élite que podía disponer, además, de recursos económicos para practicar el turismo. Hoy en día el fenómeno se ha extendido a todas las clases sociales en mayor o menor medida.

Palabras claves: Artesanía, Turismo, Variedades, Cultura, Naturaleza.

${ }^{1}$ Ciencia digital, Ambato, Ecuador, luisefrainvelastegui@cienciadigital.org 


\section{Abstract.}

Handicrafts are an important resource for tourists who like to appreciate popular expressions of art in different materials. For this reason, the handicraft of vegetable fiber (perlilla shrub) that is made in Ecuador, is a cultural and natural product that reproduces pieces such as deer, baskets, ducks and swans, but above all births, angels, sleighs and Santa Claus, which are figures associated with Christmas (period of the year in which these crafts are sold).

The binomial natural resources and culture has been successful in other countries that have seen increase the economic income of their rural populations with projects that highlight the cultural peculiarities of its people and the natural beauties of its environment. Some examples are found in Bahia, where the art and historical heritage of this city is promoted as a tourist attraction, or the case of Spain with a wide range of rural tourism based on gastronomy, associated with parties, religious events and social events, which attracts numerous tourists tasters of traditional food, who follow gastronomic routes of typical products.

The mass tourism was considered that the only ones who had free time were an elite that could also have economic resources to practice tourism. Today the phenomenon has spread to all social classes to a greater or lesser extent.

Keywords: Crafts, Tourism, Varieties, Culture, Nature.

\section{Introducción.}

\section{Origen de la artesanía}

Contraste de autores según La Colegiala (2016), El diario (2017) \& Mónica Maestud (2018), todavía no se sabe con precisión cuando se elaboró el primer objeto artesanal lo que sí sabemos es que se trata de uno de los oficios más antiguos, que fueron productos creados de forma manual sin la intervención de ningún tipo de artilugio o maquinaria, pero podríamos decir que el ser humano y el arte, están unidos por naturaleza, llevamos dentro el poder de la creación.

Se han encontrado piezas hechas manualmente de la época de la prehistoria, aunque no fue hasta el renacimiento cuando se consolidaron a los artesanos en los pueblos y ciudades. Para la conservación de las artesanías es necesario transmitir los conocimientos tradicionales, de generación en generación, es imprescindible fomentarlo ya que si no este arte podría perderse.

\section{Criterio Personal}

El origen de la artesanía viene de hace siglos atrás no se sabe en qué época exactamente pero lo que sabemos es que de la prehistoria ya que han encontrado artefactos hechos 
manualmente sin la intervención de ningún instrumento desde ahí en adelante los pueblos se han encargado de realizar las artesanías ya que no solo los hombres son encargados de realizar sino también las mujeres. Pero con el transcurrir el tiempo la artesanía ha ido decayendo progresivamente, esto es debido a que todo ha sido absorbido por las grandes superficies y producción en serie, la cual tiene menos calidad que los trabajos hechos manualmente pero cuidan la imagen que es buena y sobre todo el precio que es mucho más inferior por lo cual es bastante más competitivo comercialmente.

Figura N 1. Artesanías Guatemala

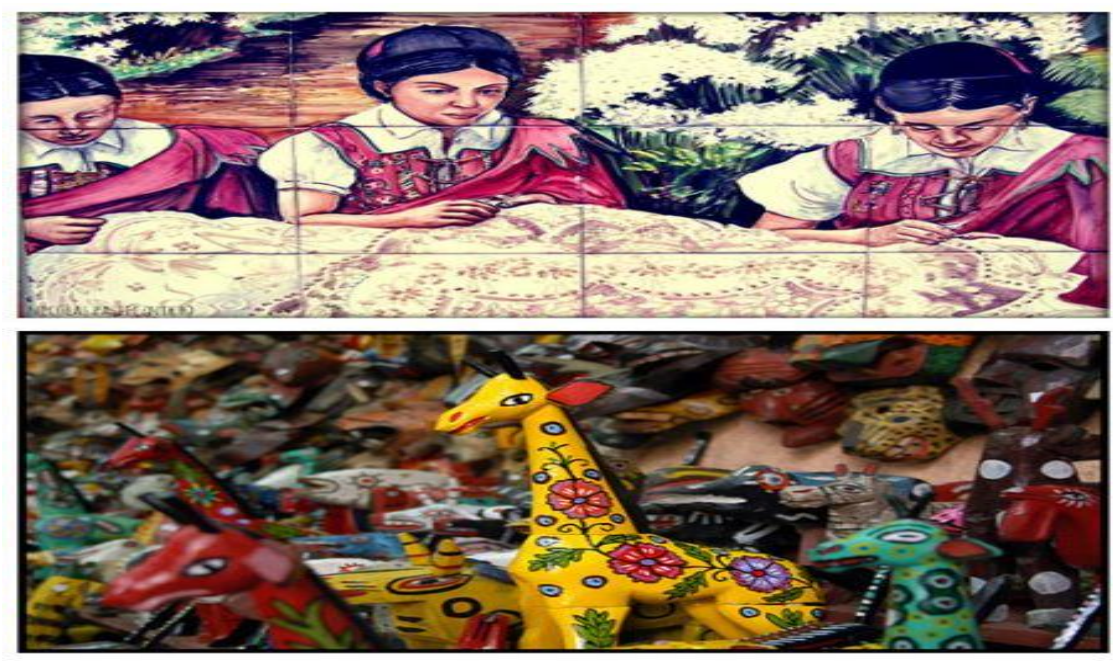

Fuente:www.deguate.com/artman/publish/turismo_general/artesanias-deguatemala_printer.shtml

Pero en la actualidad los gobiernos se están preocupando por las artesanías y gracias a eso más artesanos han vuelvo a su labor claro no como antes pero la cuestión es que no se pierda esa técnica ya que es una demostración de nuestras culturas que debe pasar de generación en generación animando a nuestros hermanos a seguir con esta labor tan linda.

\section{Desarrollo de las artesanías}

\section{Contraste de autores}

Según los autores Carvajal L. (2013), Gallo K. (2015) \& Naranjo R. (2015), Los turistas que visitan estos lugares ven artesanías con características específicas del lugar y las adquieren como souvenirs. Así, la estrecha relación entre el artesanado de base identitaria y el flujo turístico se torna cada vez más importante para el éxito de proyectos que buscan ampliar el ingreso y valorizar atributos vinculados al territorio con vistas a dinamizar su desarrollo, las artesanías de nuestros pueblos es uno de las fuentes económicas de mayor impacto ya que estos se distribuyen a distintas partes del país. 


\section{Criterio Personal}

Las artesanías pueden fortalecer la identidad cultural del lugar teniendo como colaboradores a los turismólogos, antropólogos, sociólogos, historiadores, diseñadores y artesanos dispuestos a aproximar la relación de los actores locales con el circuito espacial productivo, cultural y comercial, también actúan como medio de difusión y promueven las investigaciones sobre la importancia del artesanado en la generación de ingresos y la agregación de valor a las comunidades tanto las menos favorecidas ambientalmente en términos económicos, sociales, geográficos, de transporte y tecnología, como aquellas cuya herencia cultural está desvalorizada y desacreditada por los mismos actores locales. Cuando el turismo explota de forma sustentable un destino los cambios resultan visibles, sea por los gastos turísticos efectuados o por el consumo contemplativo y simbólico que produce.

Figura N 2. Mercado de Artesanías

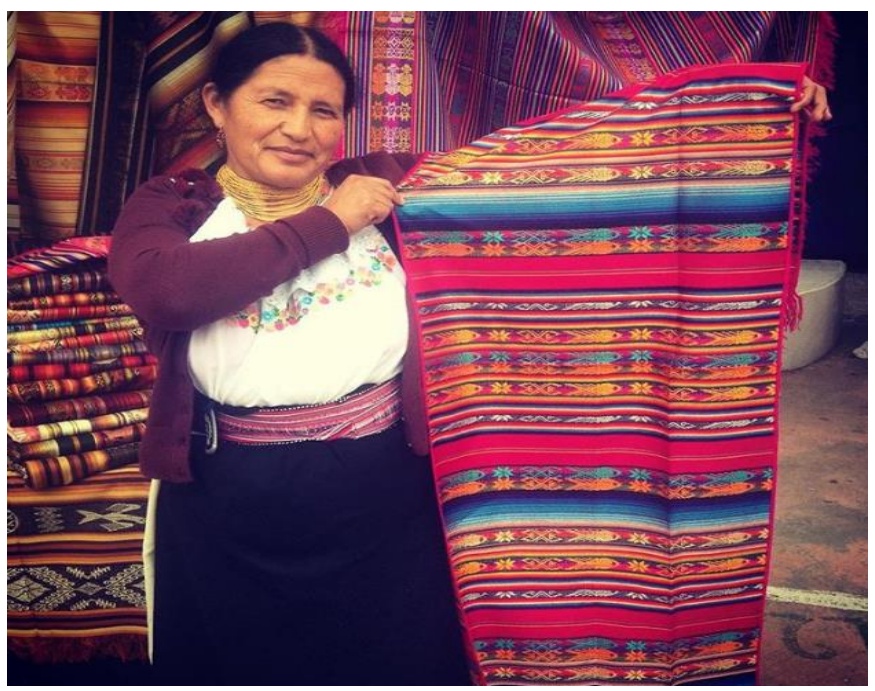

Fuente: https://matadornetwork.com/es/artesanias-ecuatorianas-mejores-souvenirsde-tu-viaje/

Por otra parte, la calidad de la madera debería adaptarse a los productos. Por ejemplo, para fabricar pequeños objetos de recuerdo no tendrían que utilizarse esencias duras de crecimiento lento y costo elevado, sino maderas de crecimiento rápido y barato. Entre los productos que atraen a los turistas, los fabricados con bambú y otras fibras naturales ocupan el cuarto puesto y representan un 5\% de la cuota de mercado. A diferencia de otros países en los que la artesanía de este tipo de fibras está desarrollada y representa una partida muy importante de las ventas turísticas, Burkina Faso carece de productos de calidad de este tipo y, además, su consumo es más bien de carácter local. 
La mejora de la fabricación de productos hechos con bambú y fibras naturales sería posible con una asistencia técnica que permitiese fabricar productos más solicitados por los turistas, es decir, más fácilmente plegables y transportables, con más colorido y más prácticos.

Los productos de cuero ocupan el quinto puesto y representan un 5\% de las ventas a los turistas. La clientela compra la marroquinería de Burkina Faso por su diseño original. Sin embargo, si la calidad de la curtimbre sigue siendo tan imperfecta como hasta ahora, ese porcentaje de ventas disminuirá automáticamente. De hecho, la clientela está acostumbrada a una calidad de cuero superior a la existente en Burkina Faso, que se está apartando cada vez más de las normas internacionales. La experiencia de la India, ha demostrado que la mejora de la calidad de la curtimbre y la conservación de los procedimientos artesanales han permitido aumentar considerablemente las ventas de los productos de cuero para los extranjeros o los nacionales.

\section{Las artesanías en ecuador}

\section{Contraste de autores}

Según los autores Campaña C. (2014), López H. (2014) \& Sarmiento J. (2016), la producción artesanal y el turismo se ha convertido en la principal actividad que dinamiza la economía del país, es la base para el crecimiento económico y ha mejorado notablemente las condiciones de vida de los indígenas, la producción de artesanías es muy buena para mejorar el turismo de las zonas y ayudar a dar un mejor impacto socioeconómico.

\section{Criterio personal}

Las artesanías se han convertido en el medio para valorizar la identidad y el arte de los pueblos a través de su artesanía, incorporándose como una actividad económica de los destinos. Así la primera se conceptualiza el turismo cultural desde la academia, el aporte a la salvaguarda del patrimonio y la función del sistema artesanal, en la segunda se contextualiza la funcionalidad de la artesanía, y la tercera se analiza la institucionalización del turismo cultural en agendas políticas del Ecuador.

Gran cantidad de destinos turísticos han tenido que enfrentarse a los efectos tanto positivos como negativos que provoca el turismo. Los retos que genera el desplazamiento masivo de personas obligan en primera instancia a conocer los diferentes impactos que se podrían presentar. 
Figura N 3. Productos artesanales de la región del Ecuador

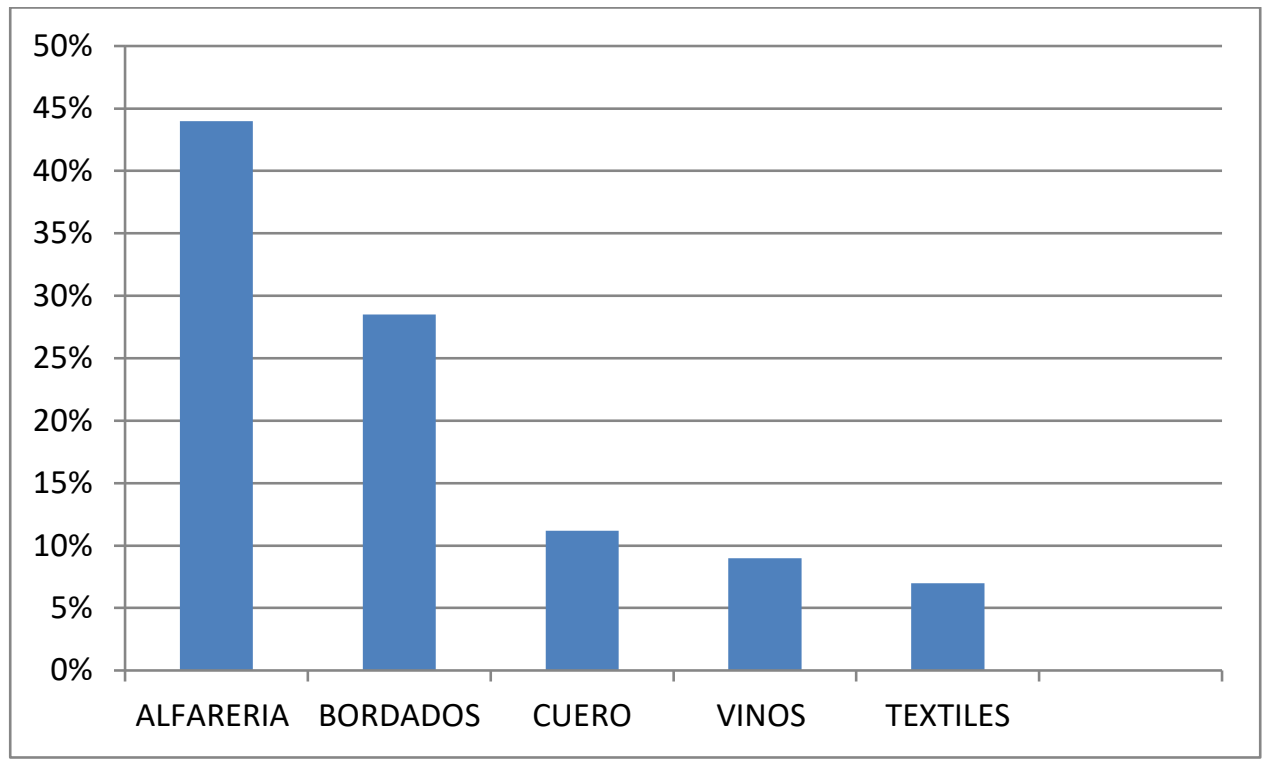

Fuente: http://www.carm.es/ctyc/institucional/turismo/EL3031.pdf

El sector artesano como parte integrante de la cultura se encuentra en continua modificación y evolución. A partir de esta premisa, se desarrolla el interrogante de partida de este artículo; El producto artesanal como producto folclórico, así como en torno al dilema arte o artesanía. Se analizaran los procesos de trasformación del producto artesanal en las industrias culturales y se reflexionara sobre los procesos de intervención (diseño, comercialización) aplicados a la artesanía popular y la relación entre artesanos, comercializadores y usuarios.

Tratar a la artesanía como parte de las industrias culturales, nos lleva a la socialización del objeto y posiblemente a alejarnos del producto tradicional, pero al mismo tiempo dota 3 a este sector de una notoriedad que ayuda a su organización y reconocimiento por parte de la sociedad. La mayor parte de los artesanos latinoamericanos no están organizados como empresas legalmente constituidas y comparten su actividad con otras ocupaciones remuneradas, puede tratarse de tareas del campo, o bien en el caso de las mujeres compartir esta actividad con las labores de cuidado del hogar y los hijos. Todo ello lleva a una infravaloración de la producción artesana.

\section{El impacto del turismo en las artesanías}

\section{Contraste de autores}

Según los autores Cruz M. (2015), Tapia P. (2015) \& Villafuerte A. (2016), el sistema artesanal es una actividad social, económica y cultural en el que coexisten diversas formas de intercambio permanente entre sus elementos en el contexto local, el impacto turístico en el Ecuador es muy grande ya que con las artesanías se puede diferenciar a las comunidades 
que esto lo rodea ya que tiene una mejor ayuda económica tanto para las familias como las comunidades.

\section{Criterio personal}

El sistema artesanal hay interacciones, conexiones que surgen de las prácticas tradiciones individuales y colectivas, esto promueve un intercambio social entre actores locales y visitantes. Es capaz de integrar elementos propios de la comunidad local y transformarlo y/o adaptarlo a su propia realidad respondiendo a las influencias emitidas por las dimensiones que rodean al sistema, se compone de cuatro elementos que interaccionan en un territorio y que permite identificarlo como tal. La actividad artesanal es el núcleo del sistema y los cuatro elementos son: el artesano, el oficio artesanal, la artesanía y el valor.

La artesanía, como producto folklórico, ha conformado rasgos distintivos de nuestra identidad, como individuos y como colectivo. Ese proceso ha estado determinado por el medio ambiente y la realidad cultural, social y económica. Las creencias, artes, valores, prácticas y tradiciones que se transmiten de generación en generación, sugieren una memoria que vive el presente poniendo en valor las experiencias ancestrales en la cotidianidad de su quehacer.

Al hablar del sector artesanal estos tres componentes no pueden separase, están interrelacionados unos con otros y son la fuente de valor como producto folklórico. La definición del sector artesano es un tema complejo ya que no existe un criterio unificado sobre qué tipo de actividades económicas pueden considerarse como artesanas. El concepto de artesanía ha evolucionado de forma diversa a lo largo de la historia y ha adoptado diferentes definiciones. En la actualidad, su definición sigue siendo heterogénea pudiendo ser analizada desde diferentes perspectivas.

Los productos artesanales son los producidos por artesanos, ya sea totalmente a mano, o con la ayuda de herramientas manuales o incluso de medios mecánicos, siempre que la contribución manual directa del artesano siga siendo el componente más importante del producto acabado. Se producen sin limitación por lo que refiere a la cantidad y utilizando materias primas procedentes de recursos sostenibles. La naturaleza especial de los productos artesanales se basa en sus características distintivas, que pueden ser utilitarias, estéticas, artísticas, creativas, vinculadas a la cultura, decorativas, funcionales, tradicionales, simbólicas y significativas religiosa y socialmente.

\section{Productos artesanales}

\section{Contraste de autores}

Según los autores UNESCO. (1997), Guizado L. (2014) \& Fontana C. (2015) la gran parte turística ayuda que los artesanos puedan distribuir sus productos y dar a conocer sobre cada 
uno de sus elaboraciones como: la fabricación manual, domiciliaria para consumo de la familia o la venta de un bien restringido, él artesano elaboran sus productos con sus propias manos en su totalidad seleccionando personalmente la materia prima dándole su propio estilo su personalidad.

\section{Criterio Personal}

La producción artesanal que conoce los aspectos simbólicos e identitarios de su oficio y posee las habilidades técnicas para materializarlos en una artesanía, en muchos de los casos el artesano tiene sello, como se describen en trabajos sobre el saber artesanal de las mujeres, y que más allá de las cuestiones de negocio y de género se plantea la tarea de entretejer el conocimiento cultural y la visión artística en una de propiedad original así lo plantea.

Actividad de transformación para la producción creativa de objetos finales e individualizados (productos específicos) que cumplan una función utilitaria y tienden a adquirir el carácter de obras de arte; actividad que se realiza a través de la estructura funcional e imprescindible de los oficios y sus líneas de producción, que se llevan a cabo en pequeños talleres con baja división social del trabajo y el predominio de la aplicación de la energía humana, física y mental, generalmente completada con herramientas y máquinas relativamente simples; actividad que es condicionada por el medio geográfico, que constituye la principal fuente de materias primas, y por el desarrollo histórico del marco sociocultural donde se desarrolla y al cual contribuye a caracterizar. La artesanía una dinámica que articula tradición y modernidad, un espacio único de creación, en donde el artesano está continuamente expresando lo que encuentra en su cotidianidad, un proceso tan cambiante como lo vivido. Efectivamente, la artesanía no es un producto estático, está en continuo cambio de la misma forma en que la cultura cambia, adaptándose y configurándose a nuevas realidades.

De acuerdo a las características de la producción, técnicas y productos artesanales desarrollados Artesanías de Ecuador, realiza una clasificación de la artesanía en indígena, de tradición popular y contemporánea o neo artesanía. Estudiaremos ahora esta clasificación, con el fin de conceptualizar la forma en que se abordará el término es esta investigación. La artesanía ecuatoriana es una expresión material de la cultura de un país donde lo indígena, lo afro y lo europeo, se han mezclado y fundido sin tener una clara división de donde empiezan o terminan. De esta forma cada producto aunque conserve rasgos particulares de la comunidad productora ha sido influenciado bien sea en sus técnicas, materiales, usos o significados, por otras expresiones culturales. De la misma manera al hablar de artesanía, hacemos referencia directa a la introducción de productos dentro de un mercado, lo cual nos lleva a pensar que el producto es influenciado por elementos nacionales e internacionales. Podemos decir que la artesanía parte de los productos "tradicionales" (lo que puede incluir técnicas, materiales, morfologías, usos o significados), pero que adopta elementos ajenos a la tradición provenientes de grupos externos al productor como una evolución propia de la identidad de individuos y colectivos inmersos en un mundo globalizado. 
Se puede entender por artesanía, la producción de objetos materiales locales que se introducen dentro dinámicas de mercado de compra venta, donde prevalece la producción manual y el uso de materias primas naturales, caracterizándose por el uso de técnicas transmitidas por tradición y por formas de creación que incluye elementos artísticos, estéticos, culturales, morfológicos, de uso y significado a las que está expuesto el artesano productor. Esta definición propia, pretende involucrar todos los aspectos antes mencionados y sentar la base para el desarrollo de este artículo. Cabe destacar de acuerdo a esta definición que la diferencia entre un producto artesanal y un objeto de la cultura material radica en la comercialización y reproductibilidad del mismo

\section{Textiles y tejidos}

\section{Contraste de autores}

Según Vega. A. (2006), Mercado de la Unión Europea (2008), \& Carrasco. E.(2013), se refiere a la creación de productos de primera y de alta calidad se trata generalmente de productos fabricados con diseño y materiales de alta calidad y precios elevados, elaborados con atención al detalle y a su acabado. En ocasiones pueden considerarse también como un tipo de arte fino. Se clasifican como productos de la alta moda a los productos que cumplan ciertos estándares muy bien definidos.

\section{Criterio personal}

En las artesanías como textiles y tejidos, en Carchi e Imbabura todavía se conservan las viejas técnicas de textiles prehispánicas pero también otras introducidas por los españoles. Entre ellas están: el hilado con el huso del sigse, la ikat, las cuales son de origen pre colombiano.

Figura N 4. Poncho indígena con técnica del ikat

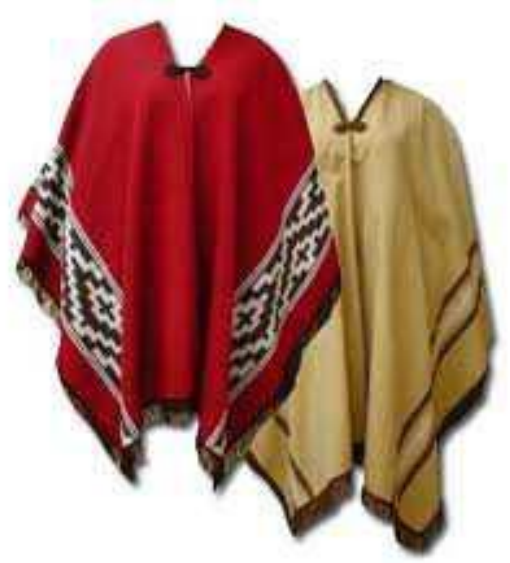

Fuente: www.tejidosikat.com 
Autor: Indígenas de la Sierra ecuatoriana

En cambio por el contario el trabajo del hilado en torno, el telar de pedales, las técnicas para el trabajo de lana y el tejido de alpargatas. Algunos de estos procesos como por ejemplo el trabajo de lana y el tejido de alpargatas se mantienen en las áreas rurales en la actualidad, en cambio el hilado con el uso del sigse, el tejido de faja y de cobijas amarradas conservan las técnicas aborígenes ancestrales.

Durante los siglos pasados los indígenas producían tejidos de lana, algodón y cabuya, además sombreros de lana para los soldados mechas e hilos de algodón para las armas, alpargatas y sogas de cabuya. Sobres esta tradición se asienta la artesanía textil practicada por los indígenas de la región interandina, aunque también hay artesanos mestizos y pequeños grupos de tejedores en las etnias de la amazonia y los Tsachilas de la costa. Los productos como el algodón nativo y la cabuya se utilizan todavía la lana de las ovejas (traída por los españoles) conserva su importancia a pesar de la (fibra sintética introducida en los años setenta).

\section{El origen de la paja toquilla}

\section{Contrate de autores}

Según Rodríguez. M (2003) Eljuri. G (2012) \& Trujillo (2012), el origen de la paja toquilla viene de Manabí, el uso de este tipo de palma vienes de épocas precolombinas. Existen, además, evidencias de que culturas ancestrales como las de Chorrera, Jama Coaque, Bahía, Guangal, Milagro Quevedo y Marteña, usaron la paja toquilla y en 1630 el indígena Domingo Choez junto esta materia prima con la forma de los sombreros españoles.

\section{Criterio personal}

El uso de la toquilla como popularmente se le conoce a esta especie de palma se puede ascender a épocas precolombinas. Varios pueblos del litoral ecuatoriano lo emplearon quedando evidente de su uso en culturas como Chorrera, etc...

El origen del sombrero de paja toquilla se la encuentran en Manabí. Cuando cae la producción del algodón y los españoles empiezan a demandar el sombrero de paja como un sustituto más liviano que el de paño. Por otro lado los tejedores de Montecristi y Jipijapa, se especializaron en la elaboración del sombrero bajo el modelo europeo.

A finales del siglo XIX La provincia de Azuay sufre una crisis de la producción agrícola por la sequía, para contrarrestar este problema y en gran medida para sacudir el establecimiento de la economía regional se complementó con el tejido de los sombreros de paja toquilla, la misma que se venía realizando décadas atrás en menor escala y que experimento una expansión sin precedentes a finales del siglo XIX e inicios del XX. 
Figura N 5. Sigsig Patrimonio Cultual

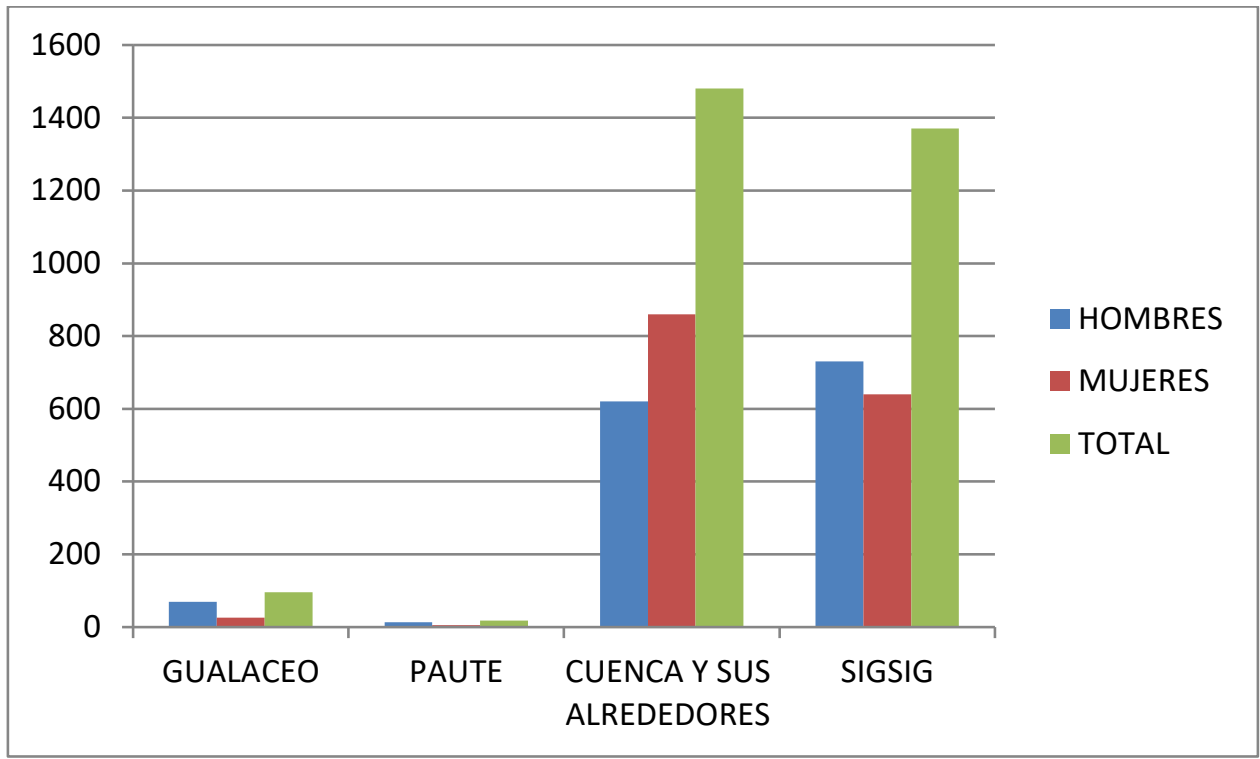

Fuente: https:sigsigpatrimoniocultural.blogspot.com/2012/12/el-tejido-de-pajatoquilla-patrimonio_11.html?m=1

Las mujeres al quedarse en el hogar tuvieron que asumir la ardua responsabilidad de velar por el hogar; por lo general eran ellas quienes tejían cuando los quehaceres domésticos, o las faenas agrícolas dejaban las manos libres, permitiendo de esta manera la subsistencia de la economía familiar y local.

En la actualidad los espacios conquistados son por las mujeres se va fortaleciendo, hay organizaciones de comunidades o pueblos se dice que es un trabajo de hormiga pero con voluntad y tenacidad de mujer

\section{Las artesanías como fuente de trabajo}

\section{Contraste de autores}

Según los autores Gallo K. 2015, Naranjo R. 2015 \& Zambrano B. 2013, las artesanías es una nueva forma de fomentar el turismo y ayuda a crear nuevas fuentes de trabajo ayudando a tener un buen impacto en el turismo.

\section{Criterio Personal}

Este tipo de turismo se caracteriza principalmente por el liderazgo que asume la comunidad local en la propuesta de atractivos turísticos. Este liderazgo se traduce en que es la propia comunidad que la planifica o programa el tipo y forma de las actividades turísticas, es quien presta los servicios y quien recibe los beneficios que se generan de las artesanías que son echas de los siguientes materiales como por ejemplo: las algas, spondylus, granos de arroz, 
cuarzo, maderas específicas, piedras, huesos, incluso fósiles u otros elementos que el propio artesano recoge en la comunidad. El turismo comunitario promueve la autenticidad de las actividades turísticas al ser desarrolladas por la comunidad anfitriona, posibilita un intercambio cultural real con el visitante (turista), en virtud que pueda profundizar en las tradiciones, costumbres y formas de vida del día a día en la comunidad.

\section{Conclusiones}

- La artesanía es un patrimonio cultural que puede convertirse en una alternativa de turismo rural y generar fuentes de empleo en las comunidades rurales, ya que efectivamente es una alternativa, pues el trabajo artesanal es una actividad relevante que da empleo a muchos grupos domésticos dentro de la comunidad.

- El turismo rural permitiría a los artesanos y artesanas obtener beneficios, pues ésta sería una forma de dar a conocer sus productos. También se necesitaría diversificar sus diseños artesanales combinándolos con los arreglos florales que elaboran y otros artículos ornamentales, para así comercializarlos durante todo el año.

- Los artesanos se enfrentan a grandes problemas de administración y organización para que la actividad artesanal sobresalga. Por eso es importante la promoción de actividades tendentes al desarrollo de la artesanía, con el fin de darle permanencia y estabilidad al proceso, convocando para este efecto a entidades estatales y municipales que tengan interés en el sector artesanal y así posibilitar el apoyo organizacional, financiero y de infraestructura.

- Actualmente los artesanos(as) cuentan con muy pocas posibilidades de apoyos gubernamentales que propicien espacios de participación, en donde se promuevan y comercialicen sus productos. Las artesanías, junto con otros atractivos culturales y naturales, convierten al Ecuador en una zona con gran potencial desde el punto de vista del turismo rural y el desarrollo sustentable.

\section{Referencias bibliográficas.}

Campaña, C. (2014). Desarrollo de las artesanias de Ecuador. Macas, Ecuador.

Carvajal, L. (2013). Las artesanias del Ecuador. Quito, Ecuador.

Cruz, M. (2015). El impacto del turismo en las artesanias. Quito, Ecuador.

Delagado, M. (2012). Medios por donde se difunde informacion de las artesanias. Latacunga, Ecuador. Obtenido de https://www.semana.com/especialescomerciales/articulo/turismo-artesanal-una-mirada-al-patrimonio-culturalcolombiano/429530-3

Fontana, C. (2015). Las artesanias y su impacto turistico. Quito, Ecuador. 
Gallo, K. (2015). La Artesanía en los oficios tradicionales. Guayaquil, Ecuador.

Guizado, L. (2014). El sector artesano en convivencia de los turistas. Quito, Ecuador.: ESPE.

Lopez, H. (2014). Las artesanias distribuidas a nivel mundial. Buenos Aires, Argentina.

Naranjo, R. (2015). Otavalo como fuente primordial de las artesanias ecuatorianas. Otavalo, Ecuador.

Saltos, K. (2015). Las culturas, artesanias como impacto turistico. Quito, Ecuador. Obtenido de http://hoy.com.do/la-artesania-una-oportunidad-para-incentivar-el-desarrolloturistico-del-pais/

Sarmiento, J. (2016). La produccion de artesanias en el Ecuador. Guayaquil, Ecuador.: El Comercio.

Tapia, P. (2015). El proceso de transformación de los productos artesanales. Quito, Ecuador.

UNESCO. (1997). Productos artesanales. México.

Vega, A. (2012). El turismo artesanal de la parte sierra del Ecuador. Cuenca, Ecuador.

Villafuerte, M. A. (2016). La industria de las artesanias en el turismo. Cuenca, Ecuador.

Zambrano, B. (2013). Las utilidades de las artesanias en el pais. Cuenca, Ecuador. Obtenido de https://www.fes-sociologia.com/files/congress/12/papers/3519.pdf

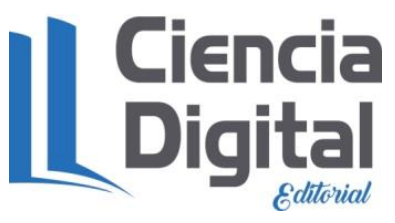


Para citar el artículo indexado.

Velasteguí López, E. (2019). Las artesanías y su real impacto en el turismo. ConcienciaDigital, 2(2), 27-40. https://doi.org/10.33262/concienciadigital.v2i2.942

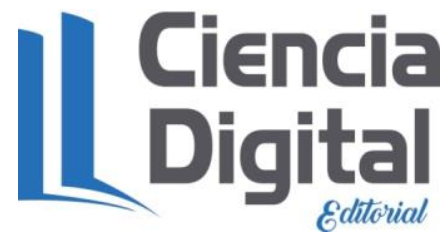

El artículo que se publica es de exclusiva responsabilidad de los autores y no necesariamente reflejan el pensamiento de la Revista Conciencia Digital.

El articulo queda en propiedad de la revista y, por tanto, su publicación parcial y/o total en otro medio tiene que ser autorizado por el director de la Revista Conciencia Digital.
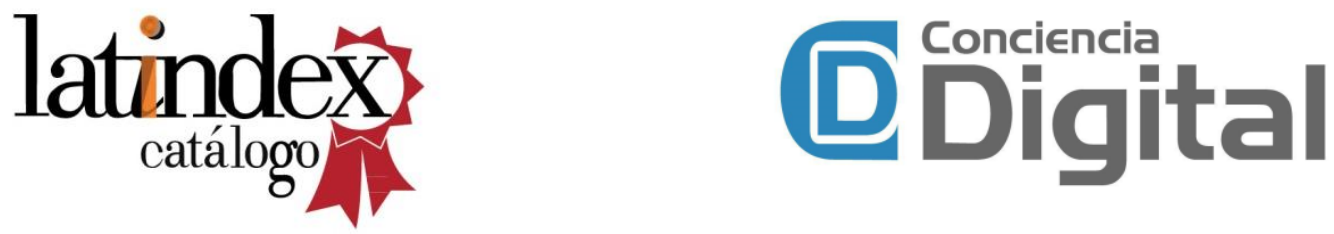